\title{
Processing of 5083 Aluminum Alloy Reinforced with Alumina through Microwave Sintering
}

\author{
Jagesvar Verma ${ }^{1}$, Anil Kumar ${ }^{2}$, Rituraj Chandrakar ${ }^{3}$, Rajesh Kumar ${ }^{4}$ \\ ${ }^{1}$ Department of Mechanical Engineering at SSIPMT, Raipur, India \\ ${ }^{2}$ Department of Mechanical Engineering at BIT, Durg, India \\ ${ }^{3}$ Department of Mechanical Engineering at CSIT, Durg, India \\ ${ }^{4}$ Department in Mechatronics Engineering at CSIT, Durg, India \\ Email: jageshwarverma28@gmail.com, Anilmech2010@gmail.com, riturajchandrakar@csitdurg.in, rajeshkumar@csitdurg.in
}

Received July 7, 2012; revised August 13, 2012; accepted August 28, 2012

\begin{abstract}
Today, there is an increasing demand worldwide for the advanced materials in order to obtain the desired properties. This is because a single material generally cannot meet the requirement of harsh engineering environment that is why the need for composites arises. Metal matrix composite is an important class of materials with high potential for structural applications requiring high specific modulus, strength and toughness. Metal matrix composites with unique properties are growing every day and widely used in different industries because of their high mechanical properties and wear resistance.
\end{abstract}

Keywords: Microstructure; Powder Metallurgy; Composite Materials

\section{Introduction}

Aluminium MMC has been of interest in the recent literature because of its lower density, high toughness and corrosion resistance in the environmental condition [1]. Aluminium MMC shows poor strength which can be improved by adding some alloying elements like $\mathrm{Cu}, \mathrm{Mg}, \mathrm{Si}$ and $\mathrm{Zn}$. The alloying elements improves strength but shows poor wear resistance properties which is the main drawback of aluminium which can be improved by adding ceramic particle such as $\mathrm{Al}_{2} \mathrm{O}_{3}$ and also using such reinforcement makes the control of microstructure, tribology and mechanical properties through controlling volume fraction, size and distribution of constituents. Among the ceramic particles $\mathrm{Al}_{2} \mathrm{O}_{3}$ is favorable since it does not react with the matrix at high temperature and does not create undesired phases [1]. Alloy and composite have been prepared i.e. Al5083 alloy and alumina as reinforcement in various weight percentages by powder metallurgy route (e.g. high energy ball milling), hot compaction, and microwave heating. Powder metallurgy method is the most suitable method for making metal matrix composites. In comparison with the melting methods, it's most important advantage is low processing temperature. That is why undesired phases between the matrix phase and the reinforcement are prevented. Moreover, reinforcement particles are also suitably distributed in the matrix [2]. Another significant feature is the production of near net-shape parts, which is cost-effective. Hardness and Wear resistance of the composite is improved by proper addition of the reinforcement. However, elongation of the composite may be reduced [3,4]. By addition of the hard phase particles, greatly improves the strength which in turn depends on the manipulation method [5]. Microwave energy is being utilized as an alternative energy source for the processing of materials to ensure rapid, volumetric heating, finer microstructure and better properties [6,7]. Researchers have established that metal powder can be efficiently heated by microwave energy. Where in the dielectric loss and eddy current loss have important roles.

In addition, multiple scattering in the powdered sample also leads to the absorption of the microwave energy. The main aim of the present work is to develop aluminum alloy matrix $\mathrm{Al}_{2} \mathrm{O}_{3}$ particulate composite and their structure property correlation. The experimental work has been classified into three parts: 1) Development of 5083Al- $\mathrm{Al}_{2} \mathrm{O}_{3}$ composite. 2) Thermal behavior analyses. 3) Characterization of $5083 \mathrm{Al} / \mathrm{Al}_{2} \mathrm{O}_{3}$ composite.

\section{Methodology}

\subsection{Development of $5083 \mathrm{Al} / \mathrm{Al}_{2} \mathrm{O}_{3}$ Composite}

\subsubsection{Raw Materials}

Aluminum 5083Al alloy was chosen for this study and alumina $\left(\mathrm{Al}_{2} \mathrm{O}_{3}\right)$ particulates were reinforced with this $5083 \mathrm{Al}$ alloy matrix. The raw materials are shown in the 
following table.

The alumina $\left(\mathrm{Al}_{2} \mathrm{O}_{3}\right)$ powders were mixed in different composition with 5083Al by four point planetary ball mill. Four different sets of metal matrix composites were prepared given in the Table 1. Initially all elemental powders were taken as its weight percentage and it was alloyed by ball mill. Then mechanically shaken powder of 10 gram mass is compacted in a rigid tool steel die using a single action hydraulic press at a pressure of $240 \mathrm{MPa}$. Graphite was used as a die wall lubricant during compaction. Sintering was done in a microwave furnace at $535^{\circ} \mathrm{C}$. After the definite holding time they were allowed to cool in the furnace itself. Sintered density is the major factor influencing the mechanical properties of the material processed through powder metallurgy. The sintered densities were calculated by rule of mixture; the samples were weighed using a Sartorius electronic balance to an accuracy of $0.001 \mathrm{~g}$. The microstructure was characterrized by using an optical microscope. Micro structural characterization was conducted in the etched conditions. Optical micrographs of selected specimens were obtained following the standard metallographic preparation. Keller's reagent $\left(0.5 \mathrm{HF}-1.5 \mathrm{HCl}-2.5 \mathrm{HNO}_{3}-95.5 \mathrm{H}_{2} \mathrm{O}\right)$ was used as a reagent. The thermal stability of alloy and composite, decomposing temperature, exothermic and endothermic properties of materials at specific heat rate, temperature and atmosphere. The analysis has been done with alumina as a reference material with gas flow rate at $20^{\circ} \mathrm{C} /$ min, temperature range $700^{\circ} \mathrm{C}$ in argon atmosphere by DSC scanning. After ball milling the elemental powder was sent for XRD study because it is one of the better tools to understand the new phase evolution, structural transformation, particle refinement and alloying formation, etc. Alloys and composites hardness were also obtained by Vickers micro hardness using a 1000 g load. Pin on disc wear tests were done at different sliding distance of 1000 m, 2000 m, 3000 m, 4000 m and 5000 m at $10 \mathrm{~N}$ and $20 \mathrm{~N}$ load.

\subsubsection{Data Analysis}

Structure Evolution of Milled Powders and Sintered Body from XRD

XRD data of Al5083 alloy and composite powder and microwave treated sample with varying weight percent (5\%, 10\% and 15\%) are shown in Figure 1, different phases such as $\mathrm{Al}_{2} \mathrm{O}_{3}, \mathrm{Al}, \mathrm{Al}_{3} \mathrm{Mg}_{2}, \mathrm{Si}, \mathrm{Mg}$ and some oxides are

Table 1. Composition of $5083 \mathrm{Al} / \mathrm{Al}_{2} \mathrm{O}_{3}$ alloy and composite.

\begin{tabular}{ccccccccccc}
\hline sample & $\mathrm{Mg}$ & $\mathrm{Mn}$ & $\mathrm{Cr}$ & $\mathrm{Si}$ & $\mathrm{Fe}$ & $\mathrm{Zn}$ & $\mathrm{Cu}$ & $\mathrm{Ti}$ & $\mathrm{Al}_{2} \mathrm{O}_{3}$ & $\mathrm{Al}$ \\
\hline 5083 & 4.4 & 0.7 & 0.15 & 0.4 & 0.4 & 0.25 & 0.1 & 0.15 & - & Bal. \\
$5 \% \mathrm{Al}_{2} \mathrm{O}_{3}$ & 4.4 & 0.7 & 0.15 & 0.4 & 0.4 & 0.25 & 0.1 & 0.15 & 2.5 & Bal. \\
$10 \% \mathrm{Al}_{2} \mathrm{O}_{3}$ & 4.4 & 0.7 & 0.15 & 0.4 & 0.4 & 0.25 & 0.1 & 0.15 & 5 & Bal. \\
$15 \% \mathrm{Al}_{2} \mathrm{O}_{3}$ & 4.4 & 0.7 & 0.15 & 0.4 & 0.4 & 0.25 & 0.1 & 0.15 & 7.5 & Bal. \\
\hline
\end{tabular}

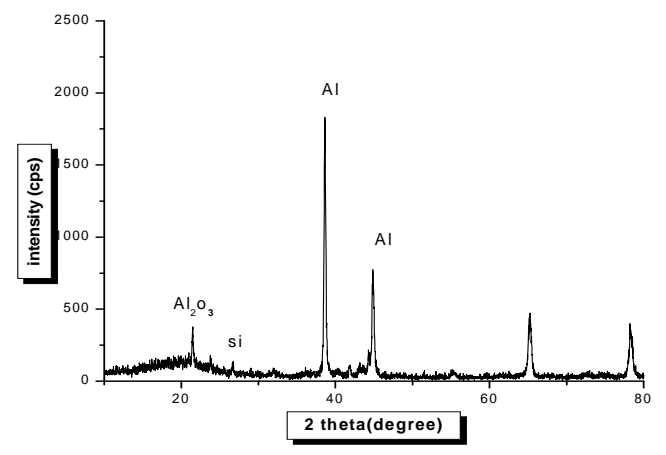

(a)

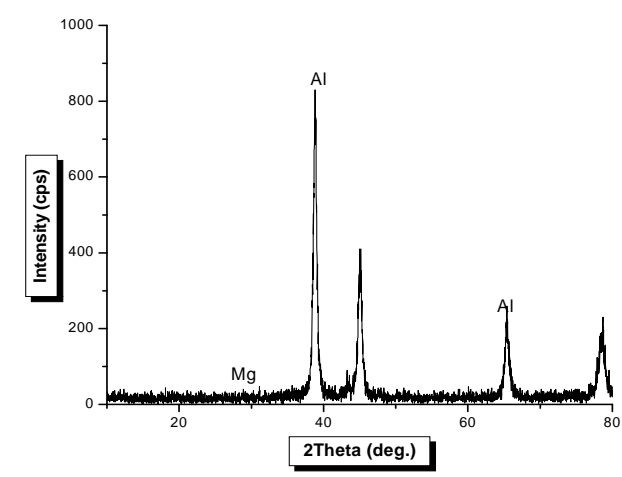

(b)

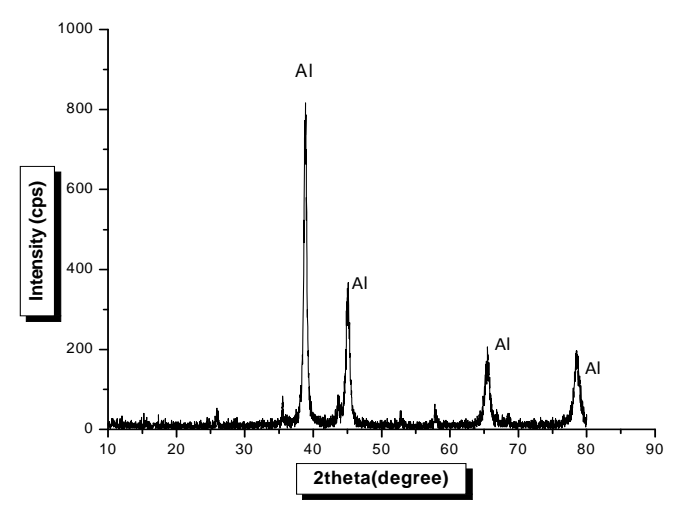

(c)

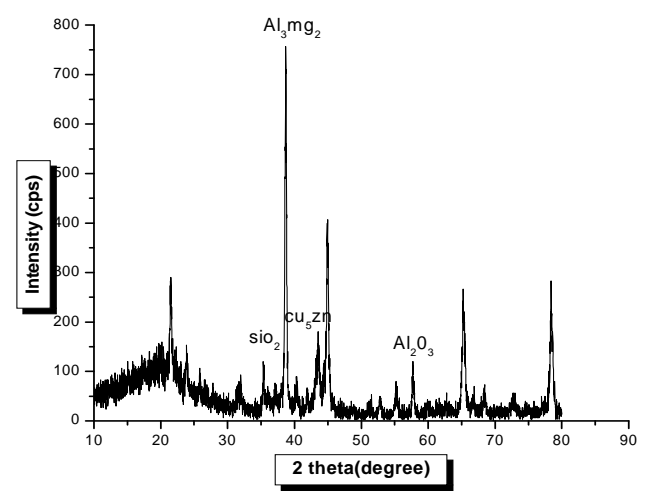

(d)

Figure 1. XRD patterns of mechanically alloyed powder and sintered sample (a) Al5083 sintered sample; (b) Al5083 powder; (c) Al5083- $\mathrm{Al}_{2} \mathrm{O}_{3}$ Composite (10 wt\%) powder; (d) Al5083- $\mathrm{Al}_{2} \mathrm{O}_{3}$ Composite (10 wt \%) sintered sample. 
confirmed, having seen both the figure of alloy powder and microwave treated sample are slightly differ, in powder alloy there is no formation of such kind of oxide layers and also peaks are somewhat broad compare to microwave treated sample the aluminums are slight shifted towards low angle. Al peaks predominantly because of initial consideration amount is very high. Oxide is formed because of temperature rise. Some inter-metallics are also formed during the mechanical alloying of Al5083 and composite $\mathrm{Mg}$ atom substituted in matrix which gives substitutional solid solution.

\subsection{Differential Thermal Analysis (DTA)}

The occurrence of amorphous phase is generally inferred by observing the presence of broad peak in the X-ray diffraction patterns. By observing broad peaks alone, it is not possible to distinguish amongst materials in which very small crystals are embedded in an amorphous matrix. So, it is desirable that the X-ray diffraction observation be confirmed by other technique as well. Thermal stability and nano-crystalline microstructures are obtained by ball milling. The analysis has been done with alumina as a reference material with gas flow rate at $20^{\circ} \mathrm{C} / \mathrm{min}$, temperature range $700^{\circ} \mathrm{C}$ in argon atmosphere. After DSC scan at heating rate $20^{\circ} \mathrm{C} / \mathrm{min}$ of 5083 alloy a peak was observed at $631.84^{\circ} \mathrm{C}$. This temperature shows the decomposition temperature of alloy. Figure 2(a), shows DSC measurements of 5083Al alloy powder. But in Figure 2(b), can see that decomposition temperature of $\mathrm{Al} 5083 / \mathrm{Al}_{2} \mathrm{O}_{3}$ composite having weight percent $10 \%$ slightly shifted to higher temperature range that is $653.26^{\circ} \mathrm{C}$ the phenomenon may be due to inhibiting effect of alumina in rearrangement of the particles.The other reason may be that the addition of alumina in aluminum matrix reduces the grain size and particle distribution increases the sintering temperature.

\subsubsection{Density Measurements}

Sintered density is the major factor influencing the mechanical properties of the material processed through powder metallurgy. Sinter densities of the compacts were determined by the rule of mixture. Powder metallurgy products are prone to porosity. Since, the composites developed in this work are focused for structural applications, the porosity estimation as well as reduction of porosity is essential. Technically, porosity is inversely proportional to density, i.e. higher porosity and lower density leads to poor mechanical and chemical property. Therefore, it is necessary to obtain good density $\mathrm{P} / \mathrm{M}$ components by adopting newer consolidation technique like hot compaction and microwave sintering. Figure 3 shows the density values of sintered materials at different composition. In fact, density of the conventional $\mathrm{P} / \mathrm{M}$ alloy is dependent on many variables such as powder morphology, particle distribution, compaction parameters, sintering parameters, etc. The density obtained in this work is around $97 \%$ of the theoretical density of aluminum/composites with the remaining 3\% porosity density
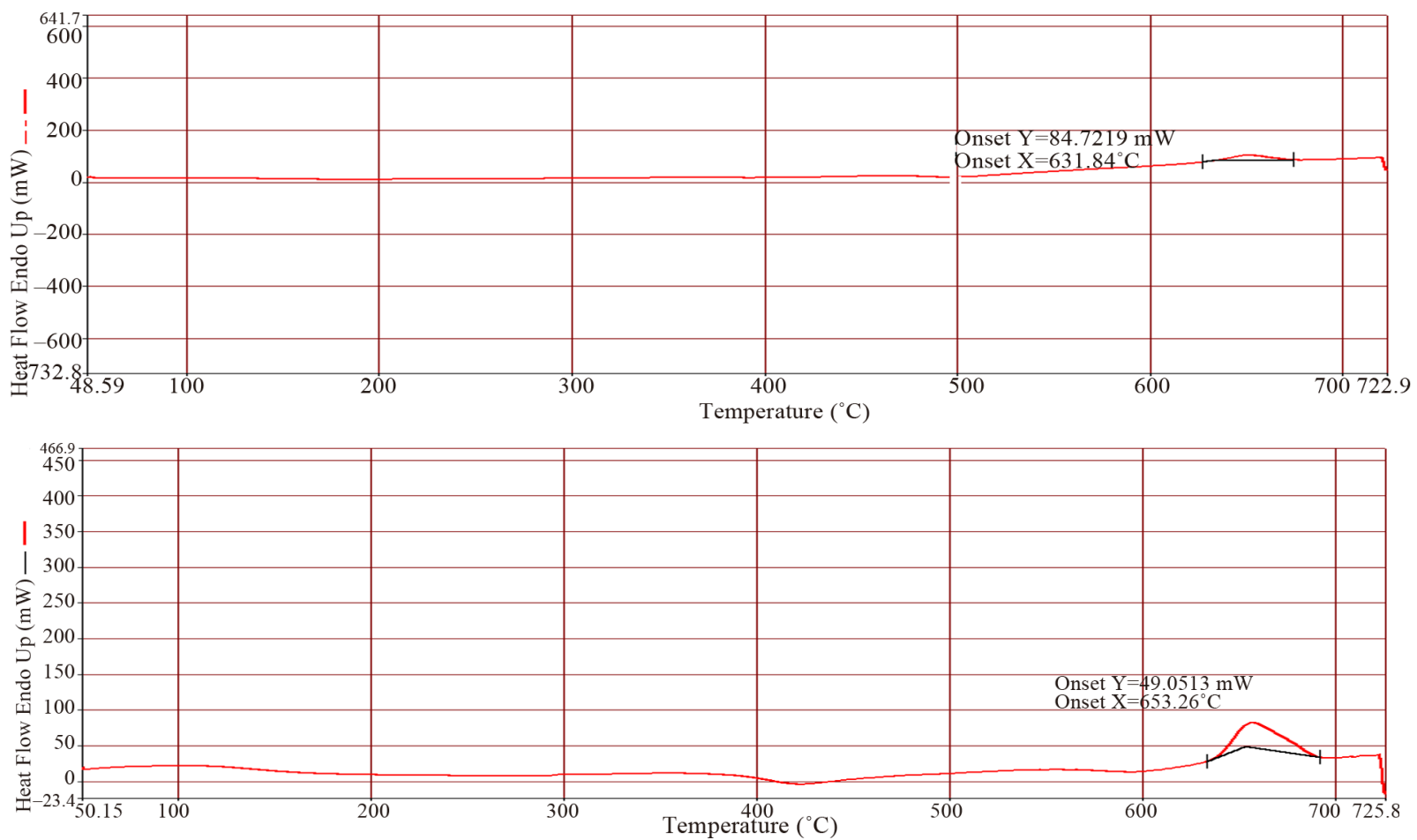

Figure 2. DSC scan at heating rate $20^{\circ} \mathrm{C} / \mathrm{min}$ of 5083 alloy and $10 \mathrm{wt} \%$ composite. 


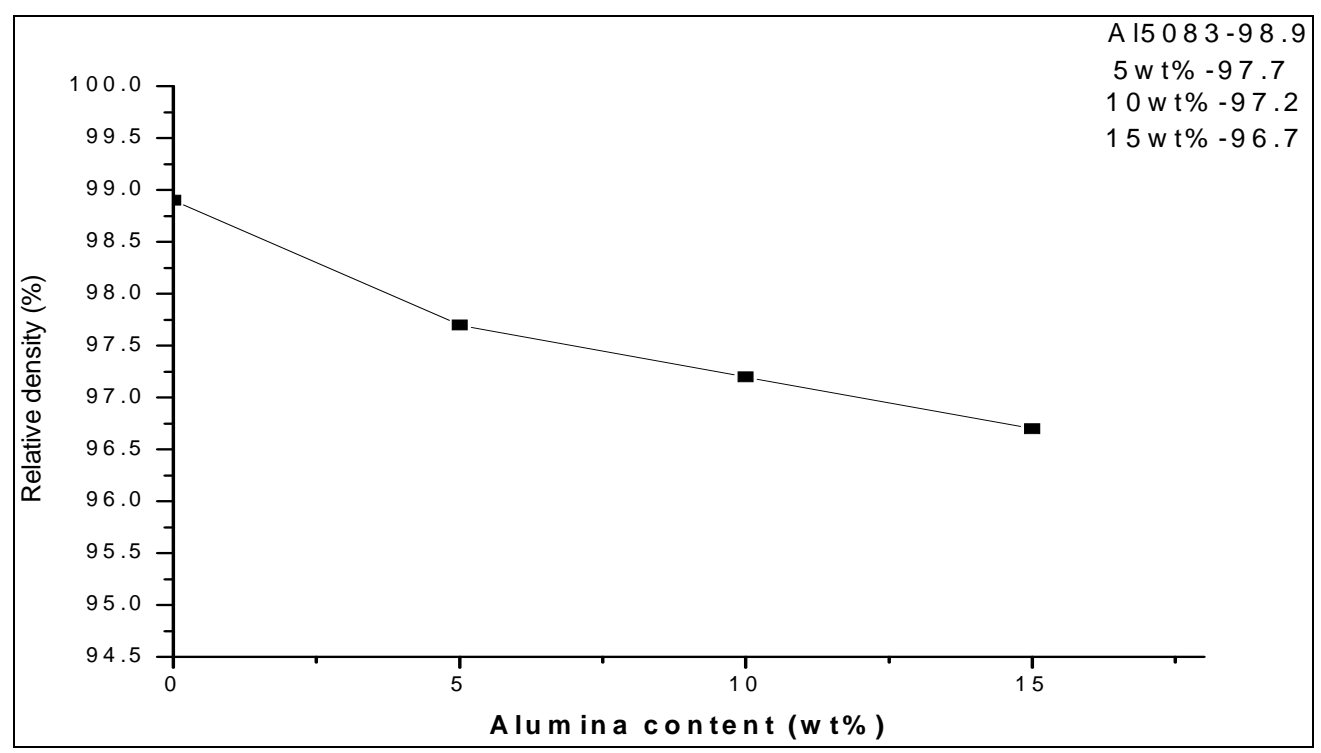

Figure 3. Relative density V/s Alumina content.

increasing due to hot compaction and microwave effect. Hot compaction gives better densification. Volumetric and rapid heating of material through microwave results in high shrinkage and less porosity. The relative density of the composite decreases compares to alloy. Due to higher hardness of alumina it decreases the pressing capacity of the sample. The result is lower density of the sample. Another reason for this phenomena is the preventive effect of alumina particles on the sintering mechanism because of high melting point of alumina $\left(2054^{\circ} \mathrm{C}\right)$ having low tendency to make bonds with alloy leading to weak network.

\subsection{Micro-Structural Characterization}

Micro-structural characterization was done using image analyzer. The micrographs are shown in Figure 4 without etched and Figure 5 etched and without etched conditions. The particles are reasonably well distributed within 5083 aluminum matrix. The interface between matrix and reinforcement could not be detected at this magnification. Metallography is one of the better tools to correlate the properties of the alloy. In our work, optical microscopy was used to understand the structural evolution, $\mathrm{Al}_{2} \mathrm{O}_{3}$ distribution in the matrix, porosity, etc. The microstructure of aluminum/composites prepared at different amounts of $\mathrm{Al}_{2} \mathrm{O}_{3}$ dispersion were studied by metallography. The structures are also observed under etched condition to study the structural changes. The microstructure revealed the respective structure with fine grain size this may be because of ball milling and microwave sintering.

\subsubsection{Hardness Test}

The hardness value increases with increasing alumina

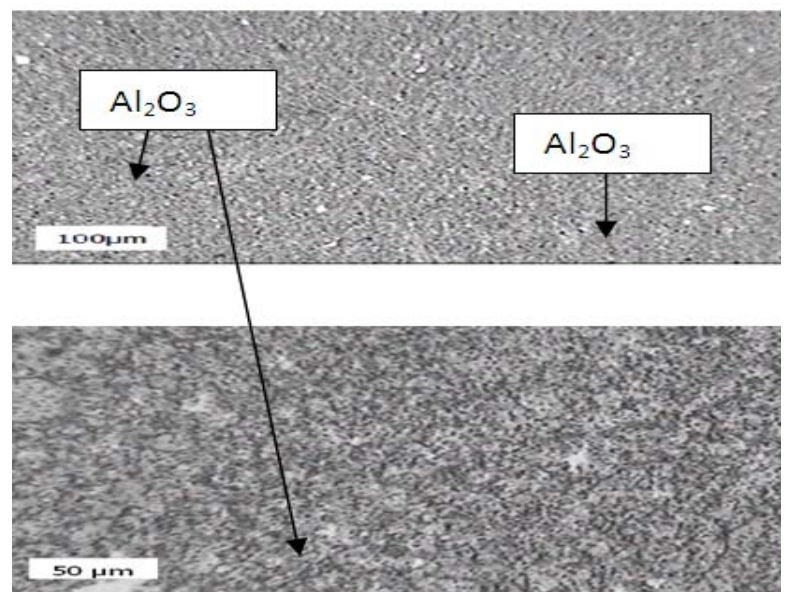

Figure 4. Micrographs of $\mathrm{Al}_{2} \mathrm{O}_{3}$ (10 and $15 \mathrm{wt} \%$ ) particles dispersed in 5083 matrix (without Etched).

content. The maximum value obtained for $\mathrm{Al} 5083 / \mathrm{Al}_{2} \mathrm{O}_{3}$ composite at $15 \mathrm{wt} \%$, shows that as the alumina content increases, the hardness value increases. The minimum value of micro hardness obtained for alloy Al5083, are shown in Figure 6. The composites show higher hardness than Al5083 alloy. The reason is because of dispersion of very fine and hard alumina particles the specific surface area is more and the dislocation cannot move easily, as the reinforcement in aluminum matrix gives higher hardness. It will provide better wear resistance.

\subsubsection{Wear Behavior}

It shows that the composite wear loss strongly depends on reinforcement loading in the composite. As the reinforcing phase content increases from 5 to $15 \mathrm{wt} \%$, the wear loss decreases. Figure 7 shows the variation of wear rate with sliding distance of $1000 \mathrm{~m}$ to $5000 \mathrm{~m}$ for the 

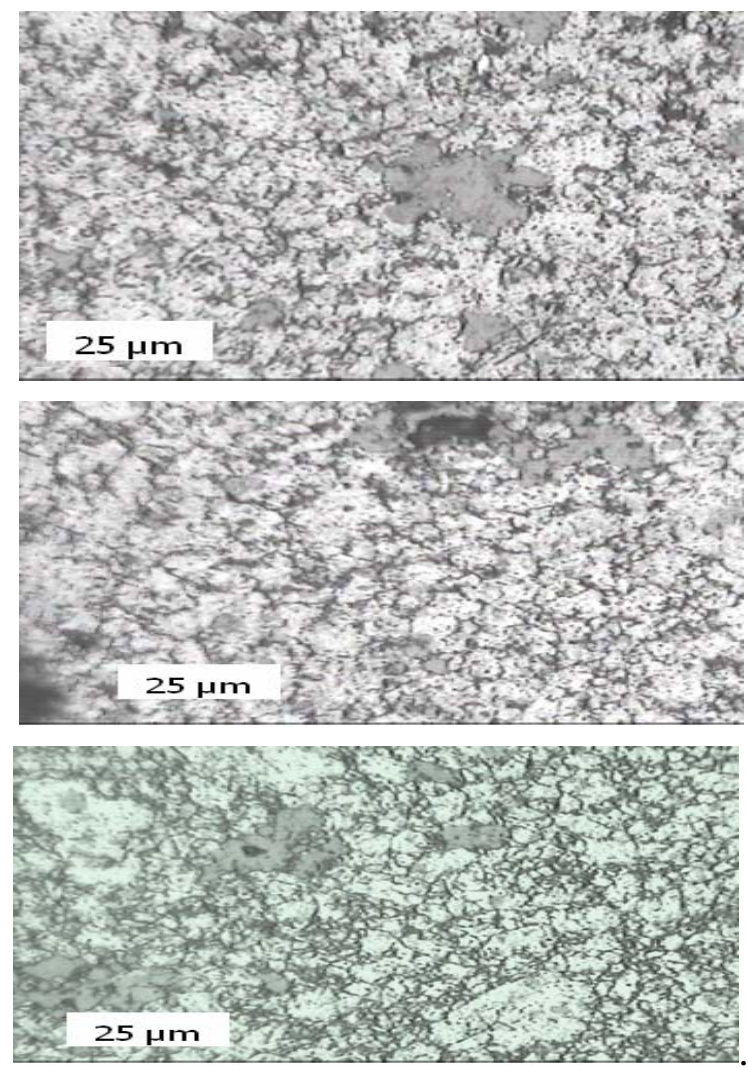

Figure 5. Micrographs of $\mathrm{Al}_{2} \mathrm{O}_{3}(5,10$ and 15 wt\%) particles dispersed in 5083 matrix (with etched).

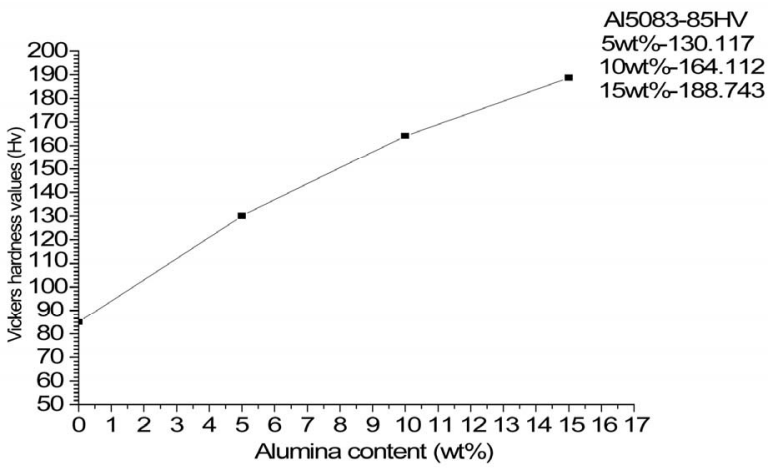

Figure 6. Hardness V/s Alumina content.

Al5083 alloy and composite alumina reinforced with 5, 10 and 15 wt\% tested under an applied load of $10 \mathrm{~N}-20$ $\mathrm{N}$ at 500 r.p.m. From Figure 7, it can be shown that increase in the applied load from $10 \mathrm{~N}$ to $20 \mathrm{~N}$ sharply increases the wear rate and with the increase in the reinforcement the wear rate is decreased. The composites with high hardness abraded at lower rates. The $\mathrm{Al}_{2} \mathrm{O}_{3}$ reinforcement phases impeded the indentation and removal by scratching of material from the surface by the abrasive particles; this resulted in the lower wear rates. It is apparent from Figure 6 that with the increase in the reinforcement, the wear rate decreases. Moreover; the wear
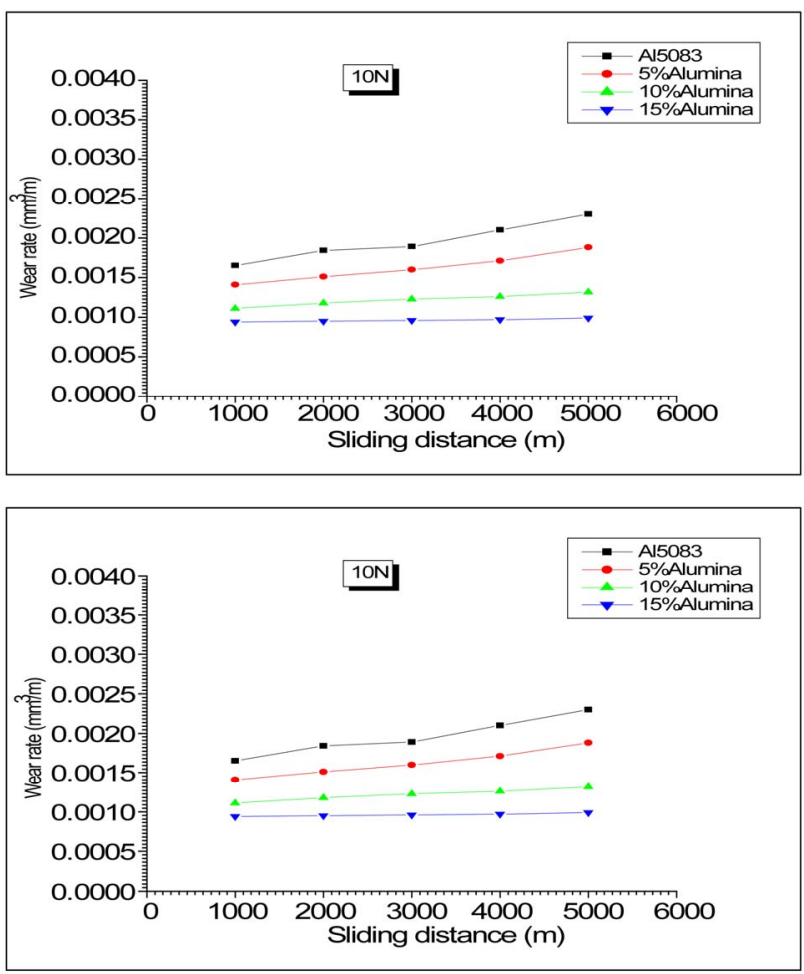

Figure 7. Wear rate vs. sliding distance at constant load $10 \mathrm{~N}$ and $20 \mathrm{~N}$ respectively.

loss of the composites increases rapidly with increasing sliding distance indicating that the counter body (En 32 steel) can deform and remove the material from composites progressively. However, a much slower increase in wear loss is observed at lower load $(10 \mathrm{~N})$ whereas, the wear loss varies almost linear with the sliding distance under specific loading conditions. The wear loss increases with the sliding distance and applied load. At higher load $(20 \mathrm{~N})$ the wear loss of the composite is high. The hardness of the counter body is 55 HRC, which is higher than the hardness of the microwave sintered Al5083 and composites. The Al5083 alloy and composites are removed by the hard counter body and this removal is faster at $20 \mathrm{~N}$ load. Since, at lower load the wear loss is very small, the mechanism operative at $10 \mathrm{~N}$ is the polishing wear. As the load is increased to $20 \mathrm{~N}$ the wear loss increases due to the plastic ploughing and grooving of alloy and composite with the higher sliding distances. At higher load and longer sliding distances the polishing wear mechanism is accompanied by the plastic ploughing and grooving wear mechanisms and cause more wear loss from the composite surface. At higher loads and less reinforcement loading $\left(5 \% \mathrm{Al}_{2} \mathrm{O}_{3}\right)$ the matrix deformation and removal is inevitable.

\section{Conclusions}

1) Solid solution of solute in Al during mechanically 
alloying was determined by XRD.

2) Powder morphology and size become uniform i.e. all powder partials were regular shape with narrow size distribution.

3) Microwave sintering of mechanically alloyed Al5083 alloy and composites resulted in good density, i.e. $97 \%$ of theoretical density.

4) The effect of alumina in 5083 alloy was studied with respect to hardness value. There was a trend that hardness value increased with increase alumina content.

5) The wear rate was low with increasing alumina content.

Aluminium 5083 alloy and composite give good response to microwave.

\section{REFERENCES}

[1] M. Kok, "Production and Mechanical Properties of $\mathrm{Al}_{2} \mathrm{O}_{3}$ Particle-Reinforced 2024 Aluminium Alloy Composites,” Journal of Materials Processing Technology, Vol. 161, No. 3, 2005, pp. 381-387. doi:10.1016/j.jmatprotec.2004.07.068

[2] J. M. Torralba, C. E. daCost and F. Velasco, "P/M Aluminum Matrix Composites: An Overview,” Journal of Materials Processing Technology, Vol. 133, No. 1-2, 2003, pp. 203-206. doi:10.1016/S0924-0136(02)00234-0

[3] L. A. Dobrzanski, A. WEodarczyk and M. Adamiak, "Structure and Properties of PM Composite Materials Based on EN AW-2124 Aluminum Alloy Reinforced with the BN or $\mathrm{Al}_{2} \mathrm{O}_{3}$ Ceramics Particles," Journal of Materials Processing Technology, Vol. 175, No. 1-3, 2006, pp. 186-191.

[4] B. G. Park, A. G. Crosky and A. K. Hellier, "Material Characterisation and Mechanical Properties of $\mathrm{Al}_{2} \mathrm{O}_{3}-\mathrm{Al}$ Metal Matrix Composites,” Journal of Materials Science, Vol. 36, No. 10, 2001, pp. 2417-2426. doi:10.1023/A:1017921813503

[5] A. Slipenyuk, V. Kuprin, Y. Milman, V. Goncharuk and J. Eckert, "Properties of P/M Processed Particle Reinforced Metal Matrix Composites Specified by Reinforcement Concentration and Matrix-to-Reinforcement Particle Size Ratio,” Acta Materialia, Vol. 54, No. 1, 2006, pp. 157166. doi:10.1016/j.actamat.2005.08.036

[6] W. H. Sutton, "Microwave Processing of Ceramic Mate- rials,” American Ceramic Society Bulletin, Vol. 68, No. 2, 1989, pp. 376-386.

[7] S. Das, A. K. Mukhopadhyay, S. Datta and D. Basu, "Prospects of Microwave Processing: An Overview," Bulletin of Materials Science, Vol. 31, No. 7, 2008, pp. 943-956. doi:10.1007/s12034-008-0150-x

[8] J. W. Kaczmar, K. Pietrzak and W. Wosinski, "The Production and Application of Metal Matrix Composite Materials," Journal of Materials Processing Technology, Vol. 106, No. 1-3, 2000, pp. 58-67. doi:10.1016/S0924-0136(00)00639-7

[9] N. H. Loh, S. B. Tor and K. A. Khor, "Production of Metal Matrix Composite Part by Powder Injection Molding,” Journal of Materials Processing Technology, Vol. 108, No. 3, 2001, pp. 398-407. doi:10.1016/S0924-0136(00)00855-4

[10] P. Yadogi, R. Peelamedu, D. Agrawal and R. Roy, “Microwave Sintering of Ni-Zn Ferrites: Comparison with Conventional Sintering," Materials Scisence and Engineering B, Vol. 98, 2003, pp. 269- 278.

[11] D. E. Clark, D. C. Folz and J. K. West, "Processing Materials with Microwave Energy,” Materials Science and Engineering: A, Vol. 287, No. 2, 2000, pp. 153-158. doi:10.1016/S0921-5093(00)00768-1

[12] D. E. Clark, D. C. Folz and J. K. West, "Processing Materials with Microwave Energy,” Materials Science and Engineering: A, Vol. 287, No. 2, 2000, pp. 153-158. doi:10.1016/S0921-5093(00)00768-1

[13] C. Leonali, P. Veronasi, L. Denti, A. Gatto and L. luliano, "Microwave Assisted Sintering of Green Metal Parts," Journals of Materials Processing Technology, Vol. 205, No. 1-3, 2008, pp. 489-496.

[14] R. R Meneges, "R.H.G.A. Kiminami, Microwave Hybrid Fast Sintering of Porcelain Bodies,” Journals of Materials Processing Technology, Vol. 190, 2007, pp. 223-229.

[15] D. Agrawal, International Symposium Advance Processing of Metals and Materials, Vol. 4, 2006, pp. 183-189.

[16] K. E. Haque, "Microwave Energy for Mineral Treatment Processes-A Review," International Journals of Minerals Processing, Vol. 57, No. 1, 1999, pp. 1-24.

[17] Y. Soydan and L. Ulukan, TAGEM-Technological Publications, Laredo, 2003. 